\title{
Fast or slow pathway ablation (or neither) for AV nodal tachycardia?
}

The recent rapid expansion of catheter ablation techniques for patients with atrioventricular nodal reentrant tachycardia (AVNRT) has been parallelled by a corresponding change in the threshold of referral for this treatment. Patients currently undergoing these procedures are often young and may not be severely symptomatic but prefer curative therapy to the inconvenience of occasional hospital admissions or prophylactic drug treatment. As a consequence it is becoming more important that the principal complication of these procedures, the development of complete heart block, is minimised. Fast pathway ablation was the first approach to be described ${ }^{1-3}$ but was discontinued in most centres following the development of a method of ablating the slow pathway with a very high cure rate and a lower risk of heart block. ${ }^{45}$ More recently several groups have demonstrated that a modified fast pathway approach can achieve comparable success rates without the occurrence of heart block. ${ }^{6-8}$ Should we be reconsidering the approach to cure of AVNRT?

\section{Modified fast pathway ablation}

The more recently described approaches to ablation of the fast pathway have incorporated a number of modifications that are likely to contribute to the increased safety of the procedure. They have in common a gradual or titrated delivery of radiofrequency energy (in terms of either power output or target temperature), and careful monitoring of AV conduction. The method of Kottkamp and coworkers $^{8}$ involves a somewhat different target site for energy delivery, albeit at a position that remains closer to the compact AV node than that used for ablation of the slow pathway. The authors of these more recent reports argue that there is little to choose between fast and slow pathway procedures. Although the almost inevitable production of a prolonged PR interval would seem to be a clear disadvantage with fast pathway ablation, there is no evidence to suggest that this is associated with any problems in the medium term.

\section{Comparison of fast and slow pathway ablation}

The obvious answer to this issue would be to perform a randomised controlled trial comparing the two techniques. One such trial has been reported ${ }^{9}$ that showed no difference in terms of efficacy or acute complications; however, it was clearly underpowered in terms of its ability to detect clinically relevant differences. The problem with comparing fast and slow pathway ablation in this way using larger numbers is that both procedures have continued to evolve, making any comparison either poorly defined in terms of the techniques being evaluated or obsolete by the time of publication. Evidence from a recent large retrospective European registry of catheter ablation procedures indicated that, in general, fast pathway ablation carries a higher risk of heart block than slow pathway ablation. ${ }^{10}$ This is perhaps not surprising given the proximity of fast pathway ablation sites to the $\mathrm{AV}$ node, and the inevitability of occasional catheter displacement during ablation of the beating heart. Indeed, distal movement of the catheter was sufficient to cause right bundle branch block in two patients undergoing modified fast pathway ablation in one series. ${ }^{7}$ It is probably fair to conclude that it is more difficult to avoid heart block with a fast pathway approach, and that a slow pathway approach is preferable for most electrophysiologists (and therefore most patients).

\section{Alternatives to fast or slow pathway ablation}

Although the slow pathway or posterior approach is the currently preferred method of ablation of AVNRT, it would be incorrect to consider that the beneficial effect of this procedure is the result of destruction of the underlying abnormality in this form of tachycardia. There is increasing evidence that the slow pathway (or at least a slowly conducting posterior atrionodal input) is universal $^{1112}$ and likely to have a function in normal individuals. The long term consequences of a damaged or destroyed slow pathway are unknown, and might include the late occurrence of complete heart block. A theoretically more attractive approach might be to target the "upper turn around" which connects the fast and slow pathways in patients with the arrhythmia, ${ }^{13}$ although the anatomic substrate for such a structure has yet to be identified. Certainly the complete destruction of the slow pathway should not be vigorously pursued as the principal aim of a posterior ablation procedure for AVNRT as this does not appear to be necessary for long term success. ${ }^{14}$ The ideal endpoint of such a procedure is the abolition of tachycardia with preservation of both antegrade fast and slow pathway conduction.

Department of Physiology,

CLIFFORD J GARRATT

Cardiovascular Research Institute Maastricht,

University of Limburg, PO Box 616,

6200 MD Maastricht, The Netherlands.

1 Haissaguerre M, Warin JF, Lemetayer P, Saoudi N, Guillem JP, Blanchot P, et al. Closed-chest ablation of retrograde conduction in patients with atrioventricular nodal reentrant tachycardia. $N$ Engl f Med 1989;320: atriovent.

2 Calkins H, Sousa J, El-Atassi R, Rosenheck S, de Buitleir M, Kou WH, et al. Diagnosis and cure of the Wolff-Parkinson-White syndrome or paroxysmal supraventricular tachycardia during a single electrophysiologic test. $N$ Engl I Med 1991;324:1612-18.

3 Lee MA, Morady F, Kadish A, Schamp DJ, Chin MC, Scheinman MM, et al. Catheter modification of the atrioventricular junction with radiofrequency energy for control of atrioventricular nodal reentrant tachycardia. Circulation 1991;83:827-35.

4 Jackman WM, Beckman KJ, McClelland JH, Wang X, Friday KJ, Roman $\mathrm{CA}$, et al. Treatment of supraventricular tachycardia due to atrioventricular nodal reentry by radiofrequency catheter ablation of slow pathway conduction. N Engl $\mathcal{Y}$ Med 1992;327:313-18.

5 Haissaguerre $M$, Gaita $F$, Fischer $B$, Commenges $D$, Montserrat $P$ d'Ivernois $C$, et al. Elimination of atrioventricular nodal reentrant tachycardia using discrete slow potentials to guide application of radiofrequency energy. Circulation 1992;85:2162-75.

6 Langberg J, Harvey M, Calkins H, El-Atassi R, Kalbfleisch SJ, Morady F. Titration of power output during radiofrequency catheter ablation of atrioventricular nodal reentrant tachycardia. PACE 1993;16:465-70.

7 Mehta D, Gomes JA. Long term results of fast pathway ablation in atrioventricular nodal reentry tachycardia using a modified technique. $\mathrm{Br}$ oventricular nodal reen
Heart $\mathcal{F} 1995 ; 74: 671-5$. 
8 Kottkamp H, Hindricks G, Willems S, Chen X, Reinhardt L, Haverkamp W, et al. An anatomically and electrogram-guided stepwise approach for

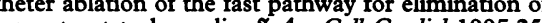
974-81.

9 Langberg JJ, Leon A, Borganelli M, Kalbfleisch SJ, El-Atassi R, Calkins H, et al. A randomised prospective comparison of anterior and posterior approaches to radiofrequency catheter ablation of atrioventricular nodal tachycardia. Circulation 1993;87:1551-6.

10 Hindrincks G. The Multicentre European Radiofrequency Survey (MERFS): complications of radiofrequency catheter ablation of arrhythmias. Eur Heart $₹$ 1993;14:1644-53.
11 Ho SY, McComb JM, Scott CD, Anderson RH. Morphology of the cardiac conduction system in patients with electrophysiologically proven dual conduction system in patients with electrophysiologically proven dua Garratt CJ, Skehan JD, Payne GE, Stafford PJ. Effect of sequential Garratt CJ, Skehan JD, Payne GE, Stafford PJ. Effect of sequential radiofrequency ablation lesions at fast and slow AV nodal pathway positions in pacients with paroxysmal atrial fibrillation. Heart 1996;75:502-8.

13 Garratt CJ, Anderson RH. Targeting the "upper-turn-around" in atrioventricular nodal reentrant tachycardia. Int f Cardiol 1995;51:283-4.

14 Manolis AS, Wang PJ, Estes NA. Radiofrequency ablation of slow pathway in patients with atrioventricular nodal reentrant tachycardia. Do arrhythmia recurrences correlate with persistent slow pathway conduction or site of successful ablation? Circulation 1994;90:2815-19.

\section{STAMPS IN CARDIOLOGY}

\section{Jean Nicolas Corvisart (1755-1821)}

The stamp was issued by France on 12 December 1964 as part of the Red Cross Fund set. The surcharge of +10 centimes is the contribution to the Red Cross Organisation. France first issued stamps to raise funds for the Red Cross Organisation in 1914 and has issued a set of Red Cross stamps each year since 1950. Illustrated here is the First Day Cover postmarked 12 December 1964 and cancelled with the Red Cross logo. The cover features the portrait of Corvisart, highlights the heart and direction of blood flow, and is inscribed vertically with the title of his book published in 1806.

The Red Cross is one of the organisations most frequently benefiting from charitable funds raised by the purchase of postage stamps. The First World War Red Cross stamps were overprints of the stamps in regular use at the time, giving the advantage of rapid production and fundraising rather than having to delay while a specific Red Cross stamp was designed, printed, and distributed. In these early stamps the time and place of overprinting varied because many were produced locally: the variable position and type of the Red Cross overprint identifies their origins.

In 1795 Jean Nicolas Corvisart became the first professor of medicine at the Charite Hospital in Paris. His Essai sur les maladies et les lésions organiques du coeur et des gros vaisseaux, published in 1806, was one of the first books on this subject and was translated into English in the United States in 1812. In it he describes a man of 48 shown at necropsy to have severe calcific aortic stenosis, in whom he diagnosed "constriction of the aortic orifice" from the "undulating and tremulous" character of the pulse. This was preLaennec, but he recognised in some cases of valve disease there was a "peculiar rushing like water" sensation which could be felt over the heart, caused, he said, by blood passing through a narrowed valve.

Corvisart became impressed by the value of the new diagnostic method of percussion which had lain dormant after its invention in 1761 by Joseph Leopold Auenbrugger, and he championed its use in clinical medicine. He popularised the use of percussion with his translation in 1808 of Auenbrugger's monograph Inventum novum ex percussione thoracis humani and always gave credit to Auenbrugger for its invention.

Corvisart was a close friend of Napoleon Bonaparte, who greatly enjoyed his company. He became his personal physician and accompanied the Emperor on his campaigns. Napoleon gave him a large carved mahogany chair which he used in his consulting room.

As a young man he originally studied law, but having visited some of the hospital clinics in Paris he decided to become a physician. This so angered his father that he was expelled from the family home, but luckily he got a job at the famous Hôtel-Dieu which enabled him to study there and gain the degree of doctor-regent in $\mathbf{1 7 8 5}$.

M K DAVIES A HOLIMAN

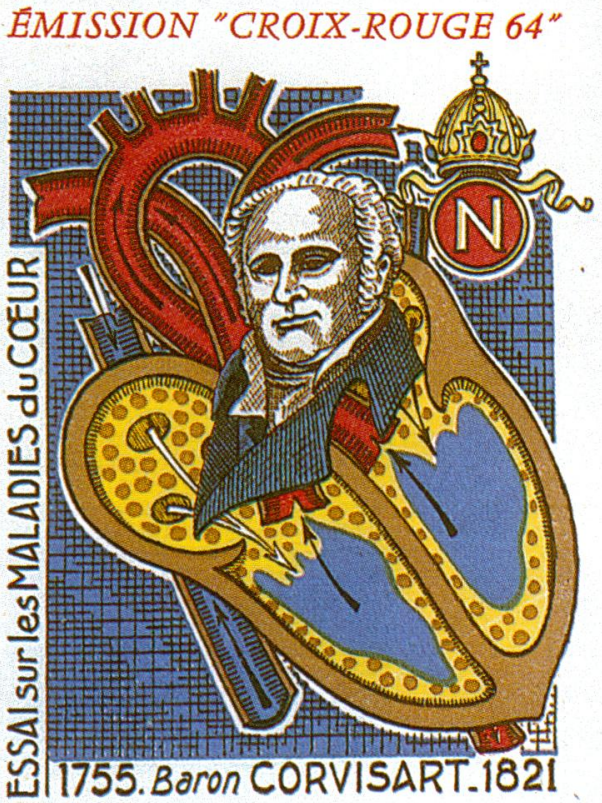

PREMIER JOUR

D.gMIS IO N

FIRST DAY COVER
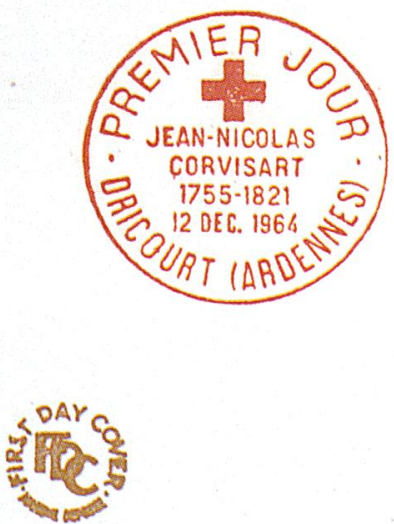